\title{
Processing and compression testing of Ti6Al4V foams for biomedical applications
}

\author{
M. E. Dizlek · M. Guden · U. Turkan · \\ A. Tasdemirci
}

Received: 31 January 2008/Accepted: 7 October 2008/Published online: 6 November 2008

(C) Springer Science+Business Media, LLC 2008

\begin{abstract}
Open cell Ti6Al4V foams (60\% porosity) were prepared at sintering temperatures between 1,200 and $1,350{ }^{\circ} \mathrm{C}$ using ammonium bicarbonate particles (315$500 \mu \mathrm{m})$ as space holder. The resulting cellular structure of the foams showed bimodal pore size distribution, comprising macropores $(300-500 \mu \mathrm{m})$ and micropores $(1-30 \mu \mathrm{m})$. Compression tests have shown that increasing sintering temperature increased the elastic modulus, yield and compressive strength, and failure strain of foams. The improvements in the mechanical properties of foams prepared using smaller size Ti64 powder with bimodal particle distribution were attributed to the increased number of sintering necks and contact areas between the particles. Finally, the strength of foams sintered at $1,350{ }^{\circ} \mathrm{C}$ was found to satisfy the strength requirement for cancellous bone replacement.
\end{abstract}

\section{Introduction}

The bulk material forms of titanium and its alloys including Ti6Al4V (Ti64) have been widely used in orthopedic

M. E. Dizlek · M. Guden $(\bowtie) \cdot$ U. Turkan · A. Tasdemirci Department of Mechanical Engineering, İzmir Institute of Technology, Gulbahce Köyu, Urla, Izmir, Turkey e-mail: mustafaguden@iyte.edu.tr

M. Guden · A. Tasdemirci

Center for Materials Research, İzmir Institute of Technology, Gulbahce Köyu, Urla, Izmir, Turkey

M. Guden · A. Tasdemirci

Dynamic Testing and Modeling Laboratory, İzmir Institute of Technology, Gulbahce Köyu, Urla, Izmir, Turkey implants due to their good biocompatibility, high strengthto-weight ratios, relative low elastic modulus, high fatigue strength, and excellent corrosion resistance as compared with widely used biomedical cobalt alloys and stainless steels [1]. Nevertheless, the porous implant components based on biocompatible metallic materials (e.g., Ti and Ti64) are known to promote interactions between bone and the surrounding tissue [2]. Pores facilitate the bone tissue formation by allowing the migration and proliferation of osteoblasts and mesenchymal cells. In addition, a porous surface provides mechanical interlocking between the implant and the surrounding bone, enhancing mechanical stability at the interface. The minimum pore size suitable for bone replacement was reported to be larger than $100 \mu \mathrm{m}$ [3], while the tendency of fibrous tissue formation increased above the pore size of $1 \mathrm{~mm}$ [4]. Furthermore, the pores are requested to be interconnected to maintain the vascular system required for continuing bone development.

Currently there are two major groups of porous implant applications: porous coatings on the bulk implants and completely porous implants. Similar processing routes namely the sintering of powder compacts and the space holder methods are used to produce biocompatible $\mathrm{Ti}$ and Ti64 powder compacts and open cell foams, respectively. Although the modulus values of sintered Ti compacts and Ti foams of varying porosities were found to be comparable with those of bone, the compressive strength values were lower than those of cortical bone due to the relatively low yield strength of Ti powder used $[5,6]$. This experimental study is therefore conducted to produce relatively high strength open cell foams that can potentially be used in biomedical applications including human cortical bone replacement. For this Ti64 foams with a porosity level of $\sim 60 \%$ were prepared using two different biomedical grade commercial Ti64 powders. The selection of $60 \%$ porosity 
was in accord with the porosity levels of the commercially available porous titanium-nickel fusion cages, $65 \pm 10 \%$ [7]. The foam samples were compression tested at a quasistatic strain rate to determine the effect of powder type and sintering temperature on the mechanical properties. The final goal of the continuing experimental program is the optimization of foam preparation process based on the microstructural and mechanical properties to satisfy the bio-mechanical design requirements for certain implants.

\section{Materials and methods}

The sintered Ti64 foams were prepared using gas atomized spherical powders (Crucible Research). The chemical composition of the powders complied with ASTM 1580-1 standard [8] as tabulated in Table 1. The sieve analyses of the powders, coded as Powder 1 and Powder 2, are listed in Table 2. The scanning electron microscope (SEM) micrographs of the powders are shown in Fig. 1a and b for Powder 1 and Powder 2, respectively. The particle size ranges between 45 and $150 \mu \mathrm{m}$ for Powder 1 and between 30 and $90 \mu \mathrm{m}$ for Powder 2. Large particles are noted to contain small satellites attached to them resulting from the powder atomization process as seen in Fig. 1a and b. Nearly $80 \%$ of the particles in Powder 1 while only about $50 \%$ of those in Powder 2 are larger than $63 \mu \mathrm{m}$, showing quite different particle distributions between the powders. Since few percentages of relatively small particles are found, the particle distribution of Powder 1 is considered nearly monomodal. On the other hand, the particle distribution of Powder 2 is bimodal, comprising relatively large $(90 \mu \mathrm{m})$ and small $(30-40 \mu \mathrm{m})$ particles as seen in Fig. $1 \mathrm{~b}$. However, it should be noted that the presence of small particles attached to large particles is expected to slightly increase the mean particle size and shift the particle distribution of the powders toward larger sizes. Ammonium bicarbonate (Aldrich) sieved in a particle size range of 315-500 $\mu \mathrm{m}$ (Fig. 2) was used as space holder by an amount of $60 \mathrm{vol} \%$. Green powder compacts of $40 \times 40 \times 10 \mathrm{~mm}$ in size were compacted at room temperature inside a tool steel die at a pressure of $400 \mathrm{MPa}$ using a polyvinyl alcohol solution ( $10 \%$ by volume) as the binding material in an amount of $2 \%$ by weight. Before sintering, the space holder was removed in a furnace at a
Table 2 Powder sieve analysis (\%) (Manufacturer's data sheet)

\begin{tabular}{lllllllll}
\hline $\begin{array}{l}\text { Opening } \\
(\mu \mathrm{m})\end{array}$ & 150 & 105 & 90 & 74 & 63 & 53 & 45 & 30 \\
\hline Powder 1 & 99.9 & 68.5 & - & 33.1 & 19.4 & 16.5 & 2.8 & - \\
Powder 2 & - & 100 & 99.3 & 69.4 & 46.2 & 39.7 & 22.6 & 2.8 \\
\hline
\end{tabular}

temperature of $200{ }^{\circ} \mathrm{C}$ for $2 \mathrm{~h}$. The sintering of green compacts was performed in a tightly enclosed horizontal tube furnace under a high purity (99.998\%) Ar flux $\left(400 \mathrm{~cm}^{3} / \mathrm{min}\right)$ at a temperature between 1,200 and $1,350{ }^{\circ} \mathrm{C}$ for $2 \mathrm{~h}$. The compacts were inserted into the furnace at room temperature inside an enclosed Ti64 box on a graphite plate which prevented the bonding between Ti box and compacts. The compacts were heated and cooled at a rate of $5{ }^{\circ} \mathrm{C}$ per min. During the heating cycle under Ar flux, the compacts were kept at $500{ }^{\circ} \mathrm{C}$ for $1 / 2 \mathrm{~h}$ in order to allow complete burning-off of the binder. The percent porosity of the sintered Ti64 foams was measured using the Archimedes' method after coating the foam sample surfaces with a thin layer of paraffin film. ThermoGravimetric Analyses (TGA) of the space holder and binder were performed using a Perkin Elmer Diamond Thermo-Gravimetric Analyzer. The microscopic analysis was performed using a Nikon Eclipse L150 optical microscope and a Philips XL30-SFEG SEM with an Energy Dispersive X-ray (EDX). The polished cross sections of epoxy-mounted foam samples were etched with Kroll's reagent $\left(3 \mathrm{~cm}^{3}\right.$ of $\mathrm{HF}$ and $6 \mathrm{~cm}^{3}$ of $\mathrm{HNO}_{3}$ in $100 \mathrm{~mL}$ of $\mathrm{H}_{2} \mathrm{O}$ ). A Philips X'pert X-ray diffraction (XRD) instrument with $\mathrm{Cu}-\mathrm{K} \alpha$ radiation was used for the phase determination.

The compression test samples were prepared by waterjet cutting of the prepared foam plates through the normal to the plate thickness as shown in Fig. 3a. Before compression testing, the cylindrical test samples (Fig. 3b), $10 \mathrm{~mm}$ in diameter and $15 \mathrm{~mm}$ in length, were cleaned in acetone to remove the cutting debris remnants. Quasi-static compression tests were conducted using a displacementcontrolled SHIMADZU AG-I universal tension-compression test machine with a cross head speed of $1 \mathrm{~mm} / \mathrm{min}$, corresponding to a strain rate of $1.6 \times 10^{-3} \mathrm{~s}^{-1}$. At least three compression tests were performed for each foam sample prepared using two different powders at different sintering temperatures.

Table 1 Chemical composition of Ti64 (wt\%) powder (Manufacturer's data sheet)

\begin{tabular}{lllllllllll}
\hline Element & $\mathrm{Al}$ & $\mathrm{V}$ & $\mathrm{O}$ & $\mathrm{Fe}$ & $\mathrm{C}$ & $\mathrm{H}$ & $\mathrm{N}$ & $\mathrm{Cu}$ & $\mathrm{Sn}$ & $\mathrm{Ti}$ \\
\hline ASTM F1580-1 & $5.5-6.75$ & $3.5-4.5$ & 0.2 & 0.3 & 0.08 & 0.015 & 0.05 & 0.1 & 0.1 & Bal. \\
Powder & 6.27 & 4.0 & 0.149 & 0.05 & 0.085 & - & 0.011 & - & - & Bal. \\
\hline
\end{tabular}


Fig. 1 SEM micrographs showing the particles in (a) Powder 1 and (b) Powder 2
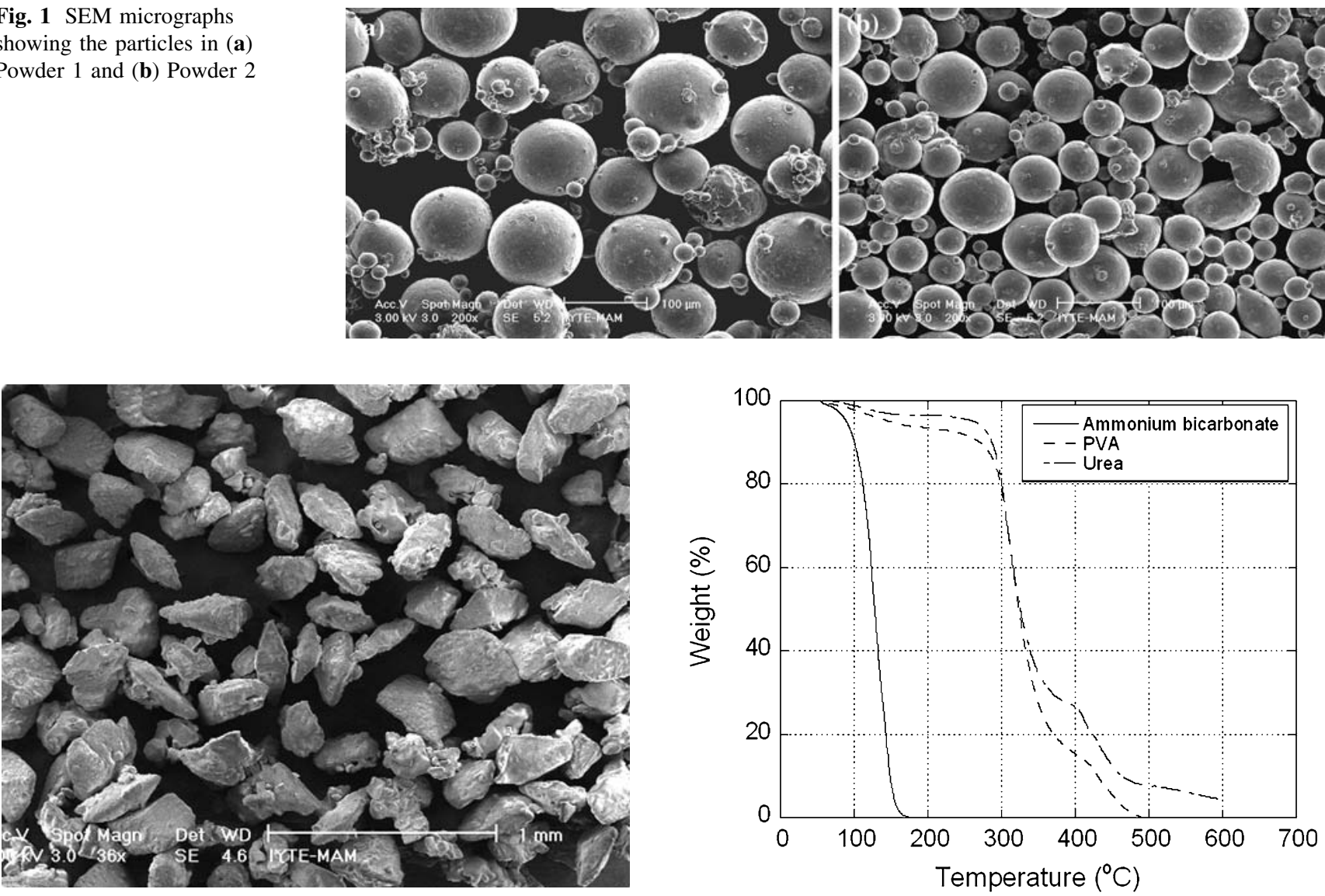

Fig. 2 SEM micrograph of ammonium bicarbonate space holder particles
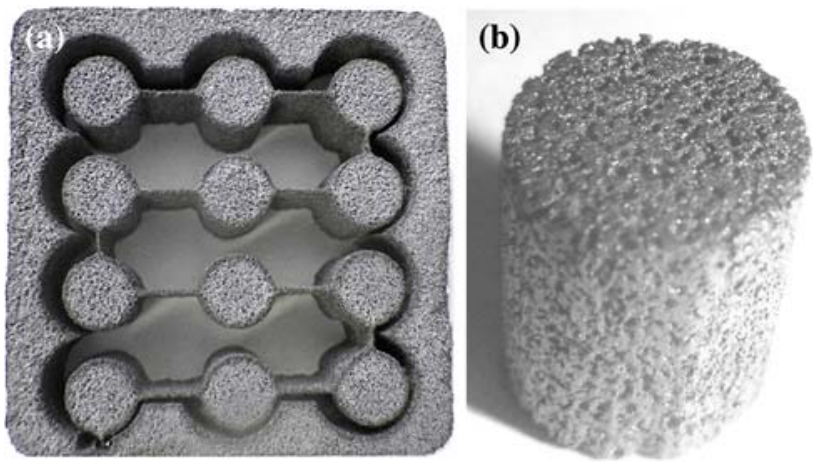

Fig. 3 (a) Water-jet cut foam sample sintered at $1,350{ }^{\circ} \mathrm{C}(40 \times$ $40 \times 15 \mathrm{~mm}$ ) and (b) cylindrical compression test sample $(10 \times 15 \mathrm{~mm})$

\section{Results and discussion}

The TGA curves of ammonium bicarbonate and PVA solution used as binder and space holder are shown in Fig. 4. As is seen in Fig. 4, ammonium bicarbonate decomposition starts above $50{ }^{\circ} \mathrm{C}$ and continues up to $175{ }^{\circ} \mathrm{C}$. PVA decomposition is however completed at a
Fig. 4 TGA curves of ammonium bicarbonate, PVA solution used in the green compact preparation, and urea

much higher temperature, $480{ }^{\circ} \mathrm{C}$ (Fig. 4). The space holder and binder removal temperatures in foam preparation were selected just above the complete decomposition temperatures, 170 and $480{ }^{\circ} \mathrm{C}$, respectively. For comparison, the TGA curve of urea (carbamide), which is commonly used as space holder, is also shown in Fig. 4. The decomposition of urea as seen in Fig. 4 is not completed until about $600{ }^{\circ} \mathrm{C}$. It was noted previously that the reaction between $\mathrm{Ti}$ powder and the cracking products of the space holder must be avoided in the temperature range of $300-600{ }^{\circ} \mathrm{C}$ to prevent the formation of interstitial solid solutions with carbon, oxygen, and nitrogen, which is detrimental for the ductility [9].

The microstructure of the as-received powder shown in Fig. 5 is composed of needle-like $\alpha$ phase, referred to as acicular alpha $(\alpha)$. The XRD spectra of the as-received Powder 1 particles and prepared foams sintered at 1200, 1250,1300 , and $1350{ }^{\circ} \mathrm{C}$ are shown in Fig. 6. The microstructure of the powders transforms from fully needle-like $\alpha$ phase into Widmanstätten microstructure of colonies of $\beta$ lathes (bcc and rich in $\mathrm{V}$ ) and $\alpha$ platelets (hcp and rich in Al) after sintering above $1,000{ }^{\circ} \mathrm{C}$. The same phase transformation was also found in Powder 2 foams. 


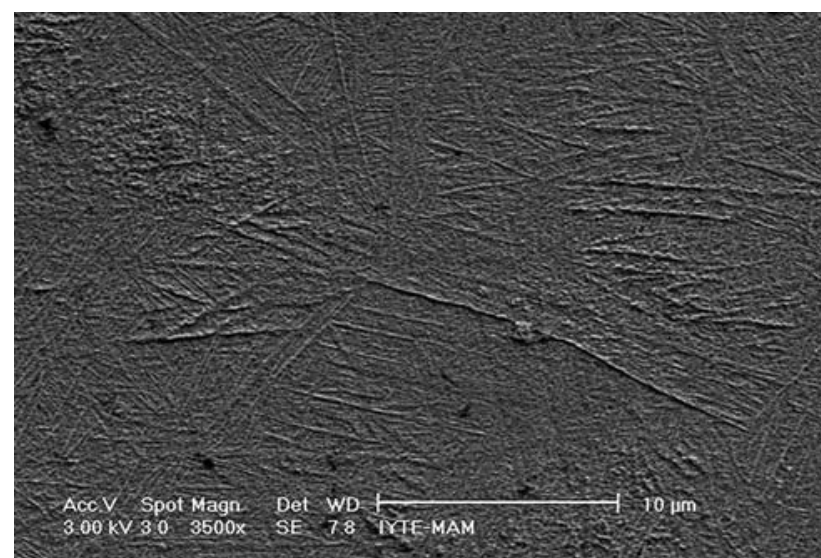

Fig. 5 SEM micrograph showing the microstructure of as-received Powder 1 particles (needle-like acicular $\alpha$ phase)

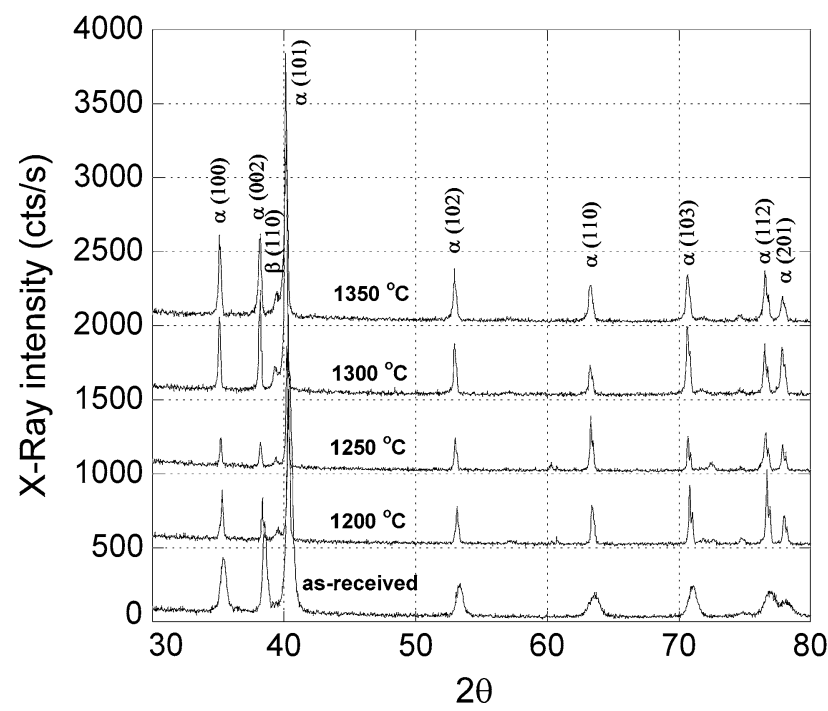

Fig. 6 XRD spectra of sintered Powder 1 foams and as-received powder

Table 3 Mean percent porosity of foams as function of sintering temperature (three measurements)

\begin{tabular}{llll}
\hline Powder & Temperature $\left({ }^{\circ} \mathrm{C}\right)$ & Mean porosity $(\%)$ & Std. Dev. \\
\hline 1 & 1,200 & 60.1 & 0.732 \\
& 1,250 & 59.3 & 0.716 \\
& 1,300 & 60.4 & 0.603 \\
2 & 1,350 & 61.6 & 0.652 \\
& 1,200 & 61.2 & 0.856 \\
& 1,250 & 61.4 & 0.658 \\
& 1,300 & 62.2 & 0.435 \\
& 1,350 & 58.1 & 0.596 \\
\hline
\end{tabular}

The percent mean porosities of the prepared foams are tabulated in Table 3 as a function of sintering temperature. The porosities of the foams vary between 58.1 and $62.2 \%$.

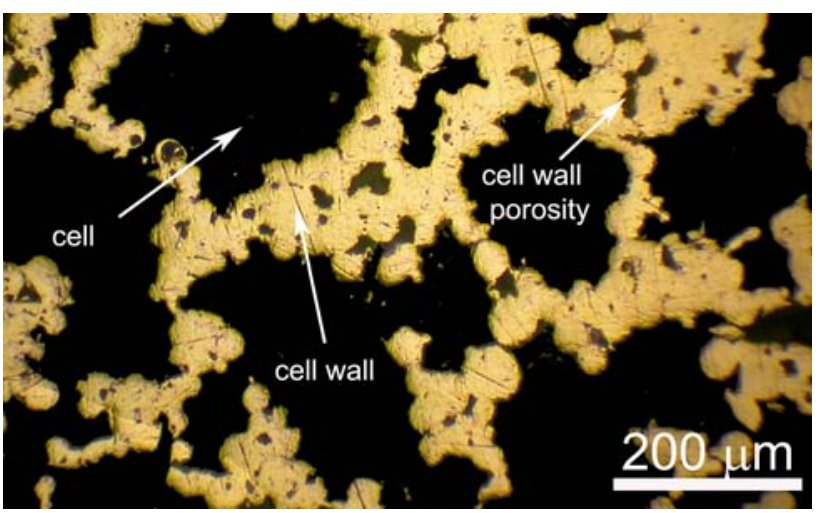

Fig. 7 Optical micrograph of Powder 2 foam cell structure (sintered at $1,300{ }^{\circ} \mathrm{C}$ )

The variations in percent porosities between the foam samples sintered at different temperatures were likely due to the variations of the amount of space holder in relatively small samples used in the porosity measurements. Nevertheless, the final porosities of the foams prepared are quite similar and correspond nearly to the starting volume percentages of the space holder.

The representative optical micrograph of the resulting cell structure of the prepared foams is shown in Fig. 7. The cellular structure of foams comprises two different pore size ranges. Relatively larger and irregular shaped cells (macropores) with the sizes of 300-500 $\mu \mathrm{m}$ result from the spaces left by the irregular shaped space holder, while smaller pores of 1-30 $\mu \mathrm{m}$ (micropores) found in between the sintered Ti64 particles in the cell walls/cell edges result from the incomplete sintering process. The micrographs of Fig. 8a and b show Ti64 particles in the cell walls of Powder 2 foam samples sintered at 1,200 and $1,350{ }^{\circ} \mathrm{C}$, respectively. The effect of sintering temperature on the sintering necks of the powders is clearly seen in these micrographs. At lower sintering temperatures (Fig. 8a) the sintering necks and/or contact areas between the particles are relatively narrower, while at higher sintering temperatures (Fig. 8b) the neck regions become thicker. Similar effects of sintering temperature on the sintering necks of the Powder 1 foams cell walls were also observed. Compared to Powder 2 foam samples (Fig. 8b), Powder 1 foam samples (Fig. 8c) show relatively fewer number of sintering necks and smaller contact areas between the particles in the cell walls at the same sintering temperature. The cell wall structure of the foams of two different powders will also be found to affect the compression mechanical responses as elaborated below.

Compression stress-strain curves of three Powder 2 foam samples sintered at $1,350{ }^{\circ} \mathrm{C}$ are shown in Fig. 9. The differences in the stress values between the individual tests are relatively small as seen in this figure. The elastic 
Fig. 8 Optical micrographs showing Ti64 particles in the cell walls: (a) Powder 2 foam sintered at $1,200{ }^{\circ} \mathrm{C},(\mathbf{b})$ Powder 2 foam sintered at $1,350{ }^{\circ} \mathrm{C}$, and (c) Powder 1 foam sintered at $1,350{ }^{\circ} \mathrm{C}$
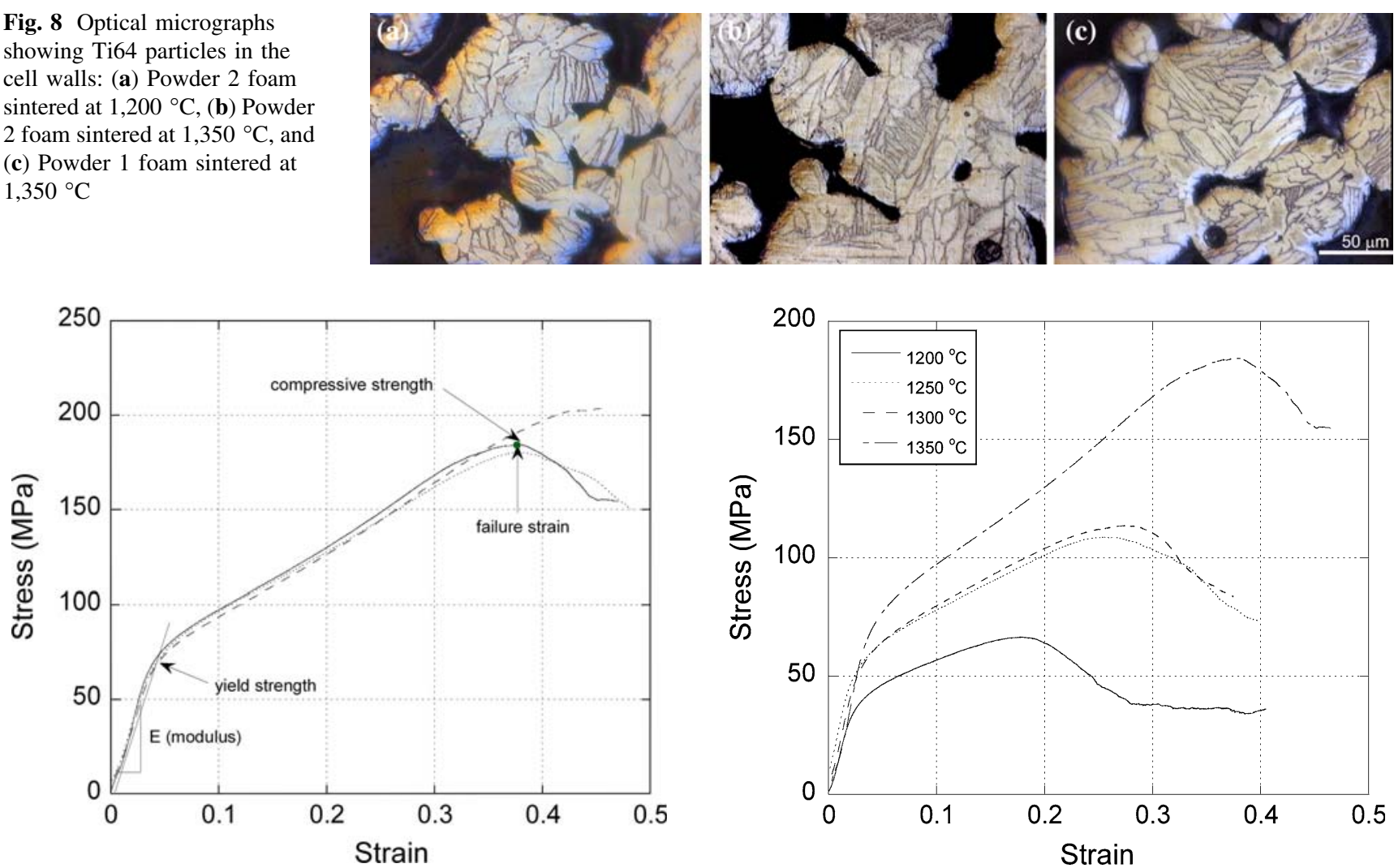

Fig. 9 Compression stress-strain curves of three Powder 2 foam samples sintered at $1,350{ }^{\circ} \mathrm{C}$

modulus and yield strength of the foams are calculated in the initial region of the stress-strain curves as depicted in Fig. 9. The stress values of foams tested increase after yielding until the maximum stress or compressive strength. The strain corresponding to the maximum stress is taken as the failure strain as shown by arrow in Fig. 9. The compression stress-strain curves of Powder 2 and Powder 1 foams are sequentially shown in Figs. 10 and 11 as a function of sintering temperature. Powder 1 and 2 foams show similar trends in compression stress-strain behavior: the initial elastic deformation is followed by an inelastic deformation until maximum stress. The effect of increasing sintering temperature is to increase the elastic modulus, yield and compressive strength, and failure strain of the foams. The elastic modulus values of Powder 1 and Powder 2 foams are tabulated in Table 4. The elastic moduli of Powder 1 and Powder 2 foams increase from 0.93 to $1.54 \mathrm{GPa}$ and from 1.49 to $2.5 \mathrm{GPa}$ when the sintering temperature increases from 1,200 to $1,350{ }^{\circ} \mathrm{C}$, respectively. The modulus of the bone was reported to vary between 1 and $20 \mathrm{GPa}$ [10]. The elastic modulus range of $60 \%$ porous Ti64 foams $(0.93-2.5 \mathrm{GPa})$ is relatively lower than that of the bone. The yield strength of Powder 1 foams increases from 22 to $50 \mathrm{MPa}$ when the sintering temperature increases from 1200 to $1350{ }^{\circ} \mathrm{C}$ (Fig. 12a). The yield

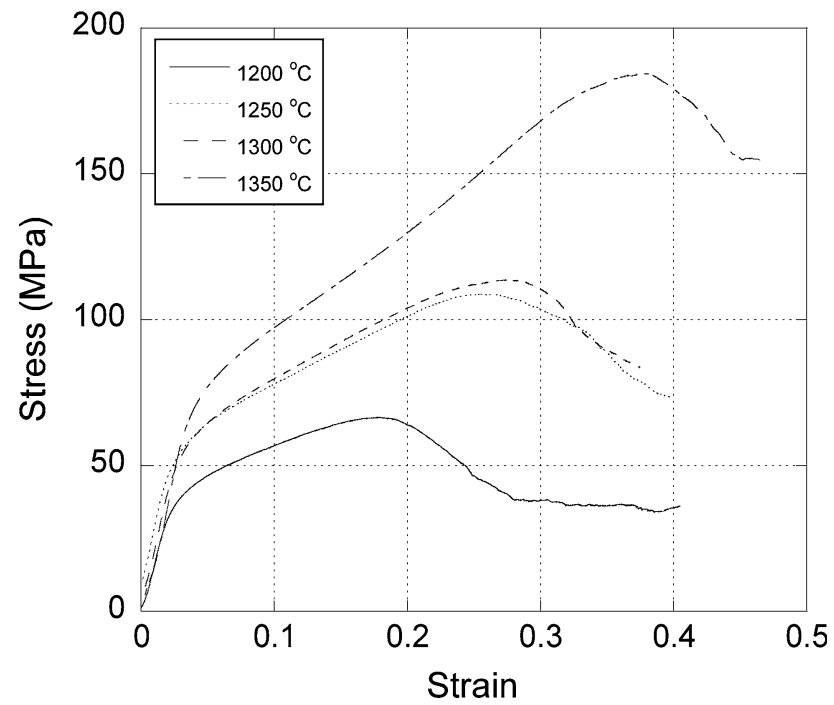

Fig. 10 Representative stress-strain curves of Powder 2 foams sintered at different temperatures

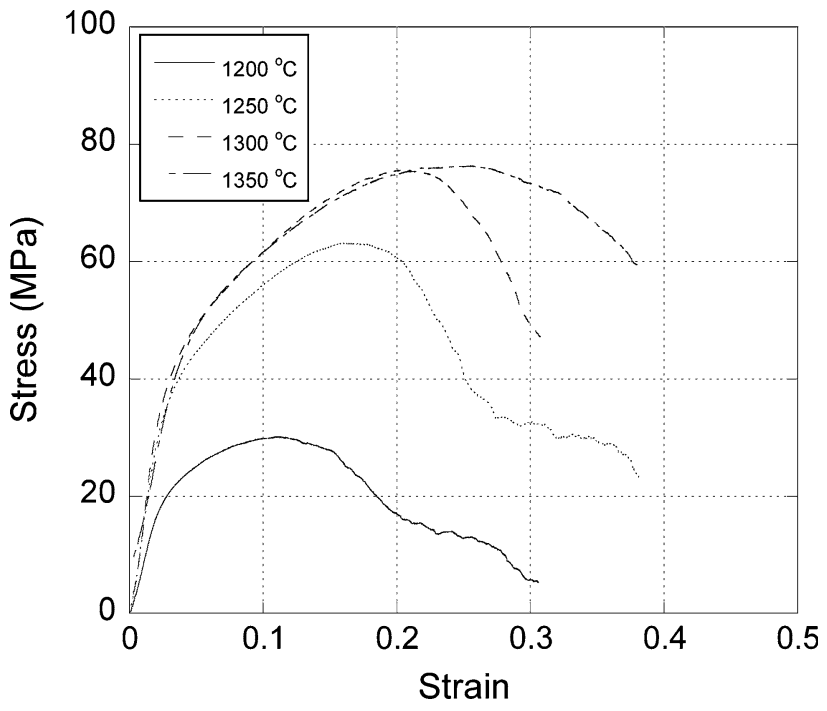

Fig. 11 Representative stress-strain curves of Powder 1 foams sintered at different temperatures

strength of Powder 1 foams increases from 42 to $75 \mathrm{MPa}$ in the same temperature range. Although sintering temperature increases the compressive strength of the foams prepared, the effect is more pronounced in Powder 2 foams as shown in Fig. 12b. This is partly due to the higher 
Table 4 Mean elastic modulus of foams as function of sintering temperature

\begin{tabular}{llll}
\hline Powder & Temperature $\left({ }^{\circ} \mathrm{C}\right)$ & Mean Modulus $(\mathrm{GPa})$ & Std. Dev. \\
\hline 1 & 1,200 & 0.93 & 0.121 \\
& 1,250 & 1.11 & 0.121 \\
1,300 & 1.44 & 0.019 \\
& 1,350 & 1.54 & 0.45 \\
2 & 1,200 & 1.49 & 0.048 \\
& 1,250 & 1.86 & 0.091 \\
& 1,300 & 1.77 & 0.070 \\
& 1,350 & 2.50 & 0.005 \\
\hline
\end{tabular}

packing ratio of Powder 2, which increases the number of contacts and bonding area between the particles. The foam samples fail in the planes $45^{\circ}$ to the loading axis as shown in Fig. 13. The failure proceeds with the separation and/or tearing of the contact zones between the particles (Fig. 14a). A close inspection on a debonded Ti64 particle shown in Fig. 14b differentiates two different modes of interparticle separation. In region A of Fig. 14b, the fracture is brittle, comprising river patterns (Fig. 14c), while the separation in region B of Fig. 14b proceeds with the ductile fracture mode, consisting of dimples (Fig. 14d).
The mechanical response of the studied foams may also be compared with those of ductile open cell metal foams and porous powder compacts. Open cell metal foams are known to show characteristic compressive stress-strain curves consisting of three distinct deformation regions: linear elastic, collapse, and densification. In the collapse region the deformation is highly localized and proceeds dominantly by cell edge buckling. This region is characterized by a long plateau stress. In densification region, the material stress increases sharply and approaches the strength of the bulk metal. The compression deformation behavior of sintered porous Ti64 powder (100-200 $\mu \mathrm{m})$ compacts of $38 \%$ porosity with an average pore size of $63 \mu \mathrm{m}$ was previously studied [11]. The compacts formed deformation zones diagonal to the sample axis at relatively low strains, 4-5\%. Particle decohesion was found to lead to the compact failure along the diagonal axis. Therefore, the foams prepared at low sintering temperatures show a compression behavior biased toward that of the sintered powder compacts. The failure strains of Powder 1 and 2 foams sintered at the lowest temperature, $1,200{ }^{\circ} \mathrm{C}$, range between 0.1 and 0.18 . At increasing sintering temperatures the foams however show partly sintered compact behavior and partly foamed metal behavior. Figure 15 compares the compression stress-strain behavior of the previously
Fig. 12 Variation of (a) yield and (b) compressive strength of foams as a function of sintering temperature
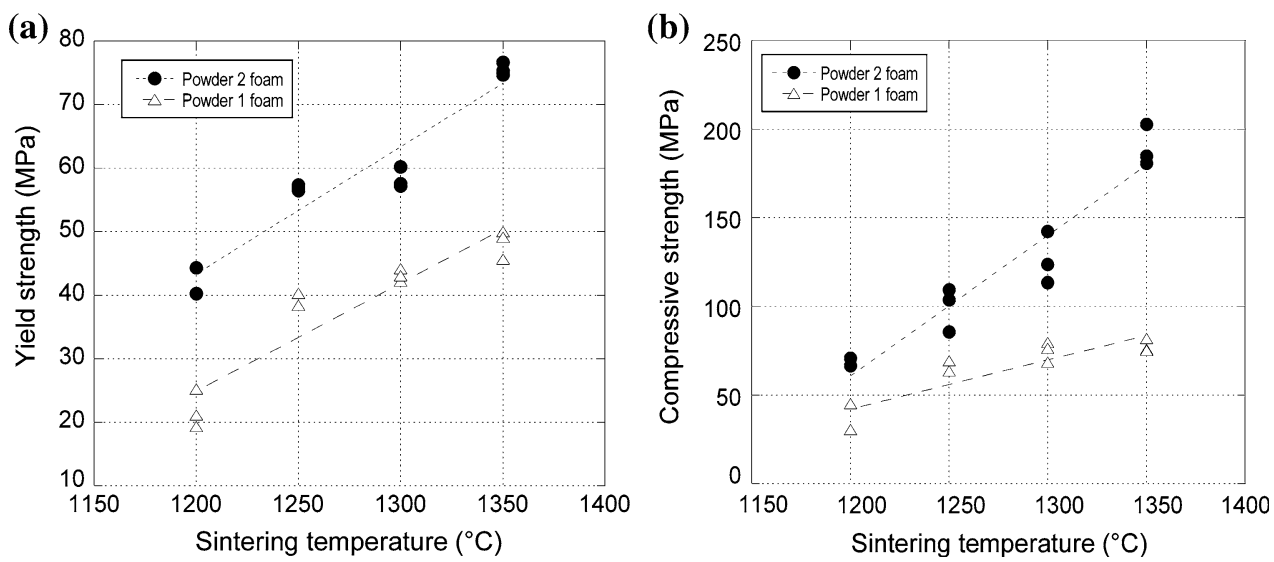

Fig. 13 Deformed samples of Powder 2 foams sintered at $1,350{ }^{\circ} \mathrm{C}$; strains (a) 0.12 , (b) $0.18,(\mathbf{c}) 0.26$, and (d) 0.4

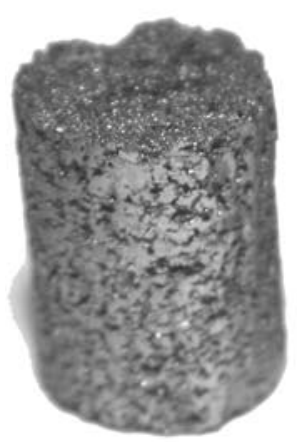

(a)

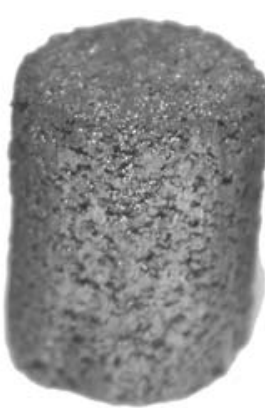

(b)

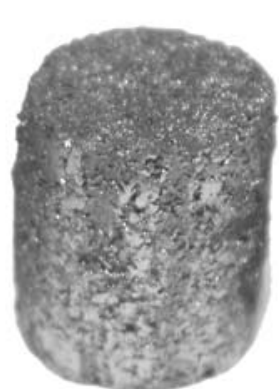

(c)

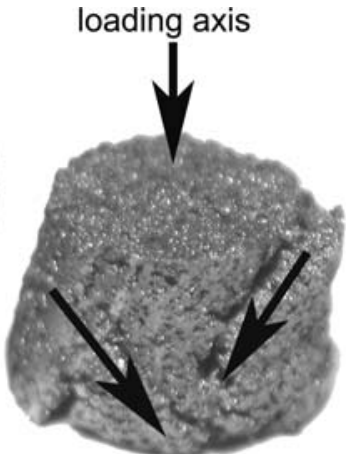

(d) 
Fig. 14 SEM micrographs of failed and separated sections of a Powder 2 foam sample sintered at $1,350{ }^{\circ} \mathrm{C}$, showing (a) debonded particles, (b) the different fracture modes in region $\mathrm{A}$ and $\mathrm{B}$, (c) brittle fracture in region $\mathrm{A}$, and $(\mathbf{d})$ ductile fracture in region $\mathrm{B}$
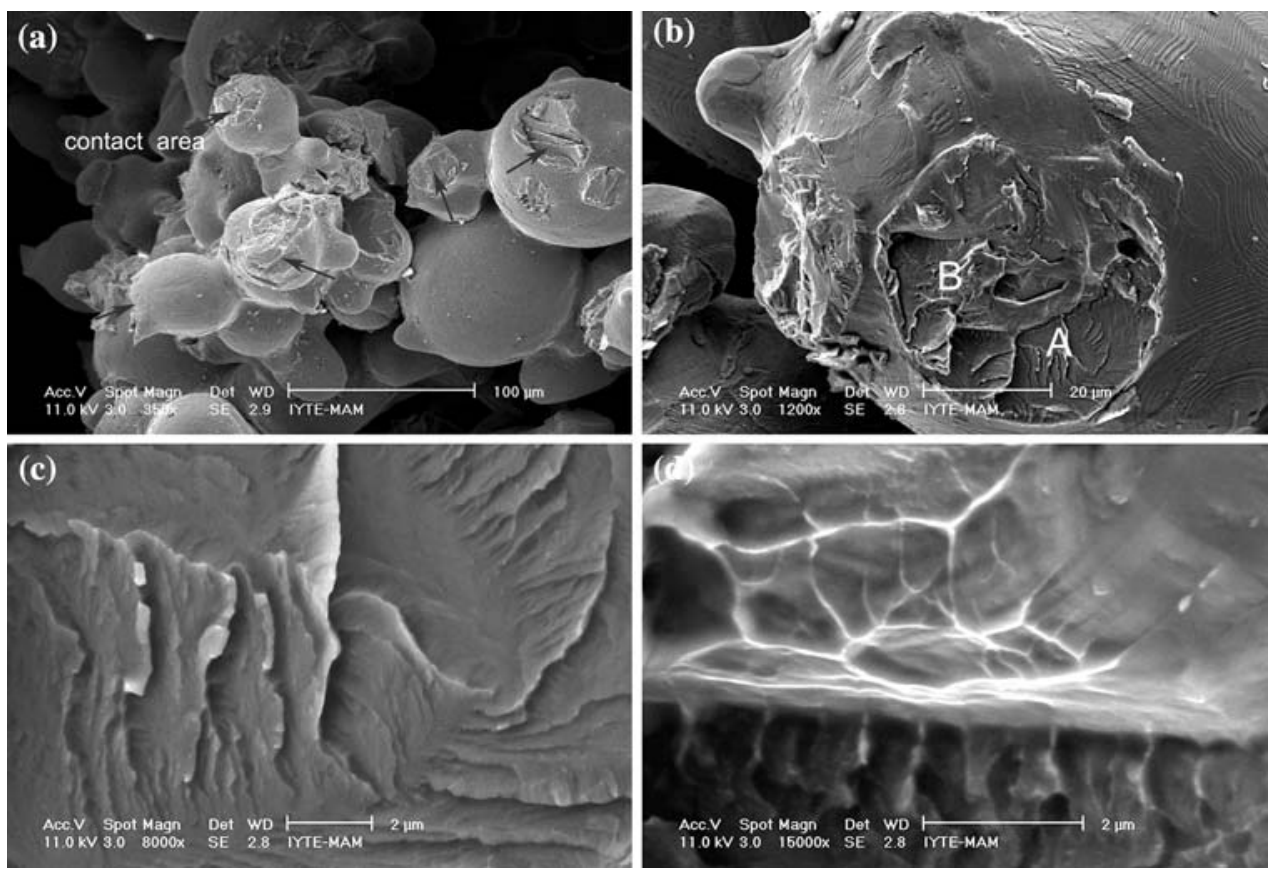

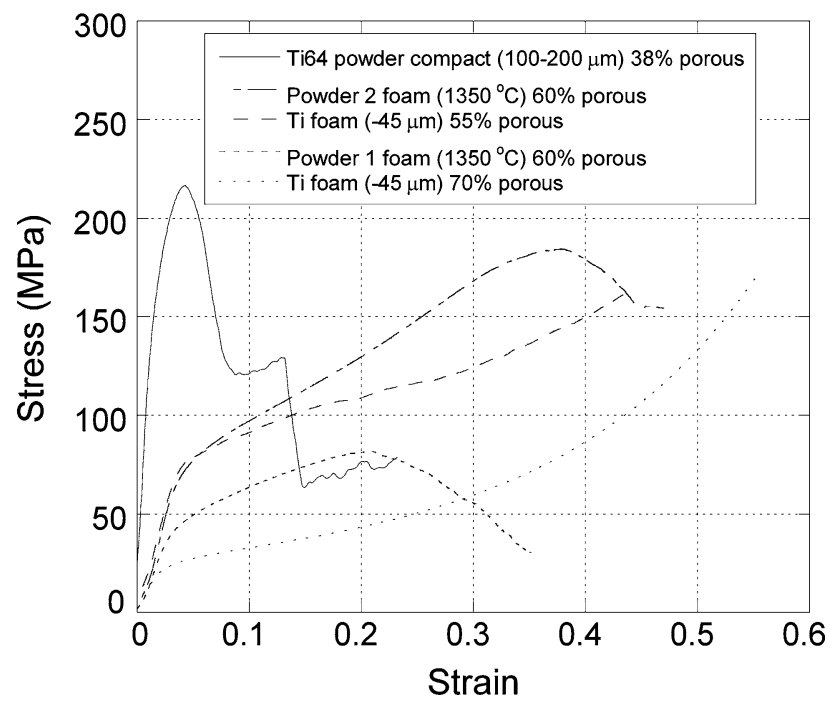

Fig. 15 Comparison of compression stress-strain behaviors of Ti64 foams with those of Ti64 powder compacts and Ti foams

studied porous Ti64 compacts [11] and Ti foams [12] with those of Powder 1 and Powder 2 foams sintered at $1,350{ }^{\circ} \mathrm{C}$. Ti foams prepared with smaller particle sizes had relatively dense cell walls/edges with small micropores (1$10 \mu \mathrm{m})$ in the cell walls and, therefore, showed compression behaviors similar to those of open cell foams. It is noted in Fig. 15 that Powder 2 foam sintered at $1,350{ }^{\circ} \mathrm{C}$ shows a yield strength similar to that of $55 \%$ porous $\mathrm{Ti}$ foam, although the former contains relatively larger micropores in the cell walls, showing the potentials of Ti64 powder use in processing stronger foams.
The strength of foams further satisfies the strength requirement for cancellous bone replacement, 3-20 MPa [13]. The yield strength of the cortical bone is however reported to be within the range of 104-121 $\mathrm{MPa}$ [14]. The potential ways of increasing yield strengths of Ti64 foams over those of cortical bone include the use of higher sintering temperatures and the powder particle distributions promoting the formation of denser cell walls, which will be further investigated.

Present results have also identified several important microstructural effects on the mechanical properties of Ti64 foams prepared by the space holder method. The powder size distribution affects the final mechanical properties of the foams by enhancing the sintering behavior of the particles. Furthermore, bimodal pore size distribution of the foams, macro $(300-500 \mu \mathrm{m})$ and micro (1$30 \mu \mathrm{m}$ ), observed in this study is well in accordance with previous studies on Ti foams prepared by the same method [6]. Nevertheless, the micropores and rough cell wall surfaces were shown to be preferable in osteoinductivity [15]. Finally, the interrelationships between porosity and pore size and the effects of compaction pressure on the final microstructure of foams should be further investigated in detail for the manufacturing of implant structures with optimum pore size and porosity.

\section{Conclusions}

In this study, 60\% porous open cell Ti64 foams were prepared using space holder method with two different Ti64 powders. In Powder 1, the particle distribution was 
nearly monomodal while in Powder 2 the distribution was bimodal. The green compacts of Ti64 and ammonium bicarbonate space holder particles $(315-500 \mu \mathrm{m})$ were sintered at temperatures between 1,200 and $1,350{ }^{\circ} \mathrm{C}$. The resulting cellular structure of foams was found to show bimodal pore size distribution: macropores $(300-500 \mu \mathrm{m})$ resulted from the space holder removal and micropores (1$30 \mu \mathrm{m})$ due to incomplete sintering of the particles. Compression tests showed that increasing sintering temperature increased the elastic modulus, yield and compressive strength, and failure strain of foams. Powder 2 foams however showed improved compression mechanical properties as compared with Powder 1 foams. The improvements in the mechanical properties of Powder 2 foams were attributed to the increased number of sintering necks and contact areas between the particles. The foams prepared showed compression behaviors somewhat between those of the sintered powder compacts and open cell foams. Finally, the strength of foams sintered at $1,350{ }^{\circ} \mathrm{C}$ was found to satisfy the strength requirement for cancellous bone replacement.

Acknowledgement The authors would like to thank the Technology Development Foundation of Turkey (TTGV) for the grant \#TTGV102/T13.

\section{References}

1. Long M, Rack HJ (1998) Biomaterials 19:1621

2. Pilliar RM (1987) J Biomed Mater Res-Appl Biomater 21:1

3. Hulbert SF, Young FA, Mathews RS, Klawitter JJ, Talbert CD, Stelling FH (1970) J Biomed Mater Res 4:433

4. Bobyn JD, Miller JE (1994) Features of biologically fixed devices. American Academy of Orthopaedic Surgeons, Chicago

5. Oh IH, Nomura N, Hanada S (2002) Mater Trans 43:443

6. Wen CE, Yamada Y, Shimojima K, Chino Y, Asahina T, Mabuchi M (2002) J Mater Sci-Mater Med 13:397

7. Assad M, Likibi F, Jarzem P, Leroux MA, Coillard C, Rivard CH (2004) Materialwiss Werkstofftech 35:219

8. ASTM F 1580-95, Standard specification for titanium and Ti6Al4V alloy powders for coating surgical implants.

9. Martin B, Stiller C, Buchkremer HP, Stöver D, Baur H (2000) Adv Eng Mater 2:196

10. Rho JY, Kuhn-Spearing L, Zioupos P (1998) Med Eng Phys 20:92

11. Tasdemirci A, Hizal A, Altındis M, Hall IW, Guden M (2008) Mater Sci Eng A 474:335

12. Guden M, Celik E, Cetiner S, Aydin A (2004) In: Biomaterials: from molecules to engineered tissues, $\mathrm{p} 257$

13. Tencer F, Johnson KD (1994) In: Biomechanics in orthopaedic trauma: bone fracture and fixation. Martin Dunitz Ltd, London, p 954

14. Burstein AH, Reilly DT, Martens M (1976) J Bone Joint Surg 58A:82

15. Chang YS, Oka M, Kobayashi M, Gu HO, Li ZL, Nakamura T, Ikada Y (1996) Biomaterials 17:1141 